\title{
High -speed Train Running Safety under Random Wind Effect
}

\author{
Liu Rong ${ }^{1, *}$, Yin Zhiqiang ${ }^{1}$ and Chen Guang ${ }^{2,3}$ \\ ${ }^{1}$ School of Mining Engineering, Anhui University of Science and Technology, Anhui 232001, China \\ ${ }^{2}$ Key Laboratory of Traffic Safety on Track (Central South University), Ministry of Education, Changsha, 410000, China \\ ${ }^{3}$ Department of Mechanical \& Mechatronics Engineering, University of Waterloo, Waterloo, Ontarion, N2L 3G1, Canada
}

Received 28 May 2021; Accepted 1 September 2021

\begin{abstract}
The aerodynamic performance of the high-speed train deteriorates in the strong wind environment when the railway vehicles have been made increasingly lighter to reach higher speeds, affecting their running safety. To explore the differences in the running safety of high-speed trains under different wind load models, the time history curve of random wind was simulated considering the random characteristic of wind using the discretizing and synthesizing random flow generation method based on the Von-Karman spectrum. Next, the aerodynamic characteristics of trains were solved and analyzed using the Star-CCM+ solver through the improved delayed detached eddy simulation technique. On this basis, the indexes of the train running safety were compared and evaluated by using the multi-body system dynamics simulation software SIMPACK. Results demonstrate that the mean values of the aerodynamic load coefficients of trains under different wind fields have little difference. The pulsation of the random wind effect becomes stronger with the increase in the yaw angle. The standard deviation of the lateral force coefficient under random wind reaches 0.238 at the yaw angle of $20^{\circ}$, greatly reflecting the aerodynamic load changes under the pulsation characteristics of a random wind effect. In terms of train running safety, the peak value of each index far exceeds the mean value under the random wind load, and the influence of the pulsation of random wind load on the train running safety indexes is enhanced with the increase in the yaw angle. When the yaw angle is $20^{\circ}$, the peak value of the train overturning coefficient exceeds $68 \%$ of the mean value, indicating that sufficient safety margin should be reserved in the evaluation of train running safety, and it is more reasonable to evaluate train running safety under a random wind field. The change curves of the running safety indexes under random wind should be filtered, and the appropriate filtering frequency is $20 \mathrm{~Hz}$. The proposed method provides a scientific basis for more accurately evaluating the train running safety under crosswind.
\end{abstract}

Keywords: High-speed train, Random wind, IDDES, Aerodynamic characteristic, Running safety

\section{Introduction}

Railway is one of the important national infrastructures, the main artery of the national economy, a popular means of transportation, and a significant part of the comprehensive transportation system. Vehicles have been made increasingly light with the continuous increase in the train running speed, resulting in the deterioration of train aerodynamic and vehicle dynamic performance, and the train running safety has been seriously compromised under a crosswind environment [1-3]. Train accidents of derailment and overturning caused by wind occur all over the world. Over 30 wind-induced train accidents have occurred in LanzhouXinjiang Railway, China. In Japan, 29 wind-induced train accidents took place from the opening of its railway operation to 2002. In 2004, a freight train derailed due to the gale in Texas, America. In 2018, the first carriage of a train running on the railway line from Montreux to Bernese Oberland, Switzerland was blown off the track. When a high-speed train suddenly encounters a strong crosswind during running, the airflow, lift force, lateral force, and overturning moment will change [4-5]. The vehicle dynamic performance will also be affected, which will greatly influence the train running state. When the train runs at a high speed under crosswind, even the crosswind with low velocity may also generate an enormous lateral force on the

*E-mail address: qianxunsen@163.com

ISSN: 1791-2377@ 2021 School of Science, IHU. All rights reserved.

doi:10.25103/jestr.144.05 vehicle body, resulting in vehicle eccentric load, derailment, and overturning, thus endangering the train running safety [6-8]. Hence, studying the aerodynamic performance and running safety characteristics of high-speed trains under crosswind is of great importance.

In the current literature, studies evaluating the train running safety under crosswind have been mostly carried out under steady wind. However, atmospheric motion has typical pulsation characteristics in reality. The evaluation of train running safety based on steady wind assumption may deviate from the practical situation. Exploring the changes in the aerodynamic and dynamic characteristics of trains running under the random wind environment is of obvious realistic significance for ensuring the safe running of the train.

Based on the above analysis, this study simulates the influence of crosswind on the running safety of high-speed trains. Subsequently, the differences in the aerodynamic performance and running safety characteristics of high-speed trains under two wind field models are comparatively analyzed, providing a reference for the safety of high-speed trains running under the actual gale situation.

\section{State of the Art}

The high-speed railway networks have enjoyed considerable development all over the world. Scholars have explored the 
aerodynamic characteristics and safety running of highspeed trains under crosswind with the increase in the train running speed. The research method advances from the field test to the wind tunnel test and numerical simulation method. Baker [9] analyzed the mass full-scale experiments data under crosswind, obtained the relationship between aerodynamic load coefficient and wind angle of attack of different vehicles, and established a static train model to explore the effects of the height and porosity of wind barrier on the train anti-overturning characteristic in case of a gale. Zhang et al. [10] acquired the aerodynamic coefficients of train and bridge by wind tunnel test, calculated the safety evaluation indexes of a high-speed train running on the bridge at different average wind velocities and running speeds, and then evaluated the train running safety through the failure probability. Zhang et al. [11] calculated the characteristics of unsteady aerodynamic force borne by the high-speed train body in the time- and frequency-domain under crosswind through the detached eddy simulation method. They also analyzed the safety of the train running under different line conditions, including flat ground, embankment, and bridge. The result showed that the safety of the train running at the leeward side of double-track embankment was the poorest.

At present, most research work on the aerodynamic characteristics of trains under crosswind has been carried out on the basis of the steady wind field environment. In reality, there is pulsation in the atmospheric motion, and some scholars have investigated the characteristics of aerodynamic and dynamic performance response based on the random wind field. Cooper [12] proposed the Cooper theory, which uses the power spectral density to represent the pulsating wind characteristics and calculated the aerodynamic load near the train under pulsating wind. Ding [13] simulated the time history curves of stormy wind related to space at the trackside and evaluated the train running safety under this wind. Baker [14] proposed the calculation method of the unsteady aerodynamic load of the train under a random wind effect through the aerodynamic admittance function via numerical simulation and wind tunnel test and established the analytical framework for the train running safety under wind effect. $\mathrm{Xu}$ et al. [15] simulated the random wind field through the power spectral density at fixed points, obtained the unsteady aerodynamic load through the quasi-steady method, and evaluated the aerodynamic characteristics and running safety of trains. Tan et al. [16] took the modified Von-Karman spectrum as the target spectrum to simulate the pulsating wind velocity time history at points moving with the train via the AR model. They also provided the aerodynamic load calculation method based on the relationship between wind velocity and wind pressure, used the aerodynamic admittance function to calculate the unsteady aerodynamic load of the high-speed train under crosswind, and compiled the MATLAB program. Yu [17] simulated three different wind load models, including steady wind, gust, and random wind, used the aerodynamic admittance function to calculate the train aerodynamic load under the random wind load, and evaluated the train overturning risk under each wind load model. The result showed that the critical wind velocity curve calculated by the gust model was slightly higher than the value calculated by the random wind model. Most above-mentioned studies assume that the wind acting on the train is steady. Some studies assume that the wind model is a gust model, while a few studies employ the hypothesis combining the random wind power spectral function and aerodynamic admittance function, which can obtain the unsteady load of trains under crosswind and consider the running safety under this load. However, the random wind field has been scarcely taken as the input in computational fluid dynamic (CFD) flow field calculation to directly simulate the aerodynamic performance of high-speed trains under random wind.

Given the deficiencies of the existing studies, this study takes the random pulsating wind field as the input wind in the CFD calculation to explore the unsteady aerodynamic load under random wind field and the train running safety under this load. On this premise, this study simulates the random wind field and analyzes the aerodynamic load characteristics of trains under steady and random wind field through the CFD numerical simulation method. Moreover, this study compares the train running safety indexes under different wind load models through the multibody dynamic simulation method.

The remainder of this study is organized as follows. Section 3 provides the method for simulating the pulsating wind and establishes the CFD numerical simulation model and multibody dynamic model. Section 4 discusses the aerodynamic load characteristics under steady and random wind fields and comparatively explores the train running safety indexes under different wind fields through the multibody dynamic simulation method. Section 5 summarizes the conclusions.

\section{Methodology}

\subsection{Pulsating wind simulation}

The random wind in nature is composed of two parts: one is the average wind with a period of over $10 \mathrm{~min}$, and the other is the pulsating wind with a period of approximately several seconds. The power spectral density function can express the characteristics of the pulsating part. According to experience, the Von-Karman spectrum is more applicable to the wind around bridges, vehicles, etc., and it is also used in EN14067 standard [18]. Therefore, this study generates the random wind using the discretizing and synthesizing random flow generation (DSRFG) technique based on the Von-Karman spectrum. Huang [19] proposed the DSRFG method for generating a turbulent velocity field satisfying target turbulence spectrum and spatiotemporal correlation based on the random flow generation (RFG) method. The principle of this method lies in discretizing the power spectrum of velocity into several segments and generating the pulsating wind field of each segment using the improved RFG method. This method is capable of modeling a randomly distributed frequency spectrum. The turbulent velocity field is generated through the following Equation (1):

$$
\begin{aligned}
& u_{i}\left(x_{j}, t\right)=\sum_{M=1}^{M} \sum_{N=1}^{N}\left[p_{i}^{(m, n)} \cos \left(k_{j}^{(m, n)} x_{j}^{-m}+2 \pi f_{n, m} t\right)+q_{i}^{(m, n)} \sin \left(k_{j}^{(m, n)} x_{j}^{-m}+2 \pi f_{n, m} t\right)\right] \\
& p_{i}^{m, n}=\operatorname{sign}\left(r_{i}^{m, n}\right) \sqrt{\frac{1}{N} S_{u i}\left(f_{m}\right) \Delta f \frac{\left(r_{i}^{m, n}\right)^{2}}{1+\left(r_{i}^{m, n}\right)^{2}}}
\end{aligned}
$$




$$
\begin{aligned}
& {\left[\begin{array}{lll}
p_{x}^{m, n} & p_{y}^{m, n} & p_{z}^{m, n} \\
q_{x}^{m, n} & q_{y}^{m, n} & q_{z}^{m, n} \\
k_{x}^{m, n} & k_{y}^{m, n} & k_{z}^{m, n}
\end{array}\right]\left\{\begin{array}{l}
k_{x}^{m, n} \\
k_{y}^{m, n} \\
k_{z}^{m, n}
\end{array}\right\}=\left\{\begin{array}{l}
0 \\
0 \\
1
\end{array}\right\}} \\
& \bar{x}_{j}^{m}=\frac{x_{j}}{L_{j}^{m}}
\end{aligned}
$$

where $i=1,2$, and 3 represent the longitudinal, transverse, and vertical velocities, respectively; $j=1,2$, and 3 denote directions $x, y$, and $z$, respectively; $M$ is the number of spectral segments; and $N$ is the random frequency number within each segment. Parameters $p_{i}^{m, n}$ and $q_{i}^{m, n}$ are defined in Equations (2) and (3). $f_{n, m}$ is a normally distributed random number with zero mean value and standard deviation $f_{m}$. $k_{i}^{m, n}$ is the coordinate of points uniformly distributed within the unit radius on the spherical surface, which satisfies Equation (4) to maintain the non-divergence condition. The dimensionless position parameters are defined and generated in Equation (5). $S_{u i}\left(f_{m}\right)$ represents the spectrum of frequency $f_{m}$ in direction $i . r_{i}^{m, n}$ is a normally distributed random number with mean value and unit standard deviation being zero. $\Delta f_{m}$ is the bandwidth of the frequency spectrum.

Figure 1 shows the comparison curves of the random wind spectrum generated by the DSRFG method with the target wind spectrum. The random wind spectrum generated by the DSRFG method accords well with the target VonKarman spectrum. Train running safety is mostly affected by the transverse wind; thus, this study mainly considers the transverse pulsation of wind. The wind velocity curve generated by this method is displayed in Figure 2.

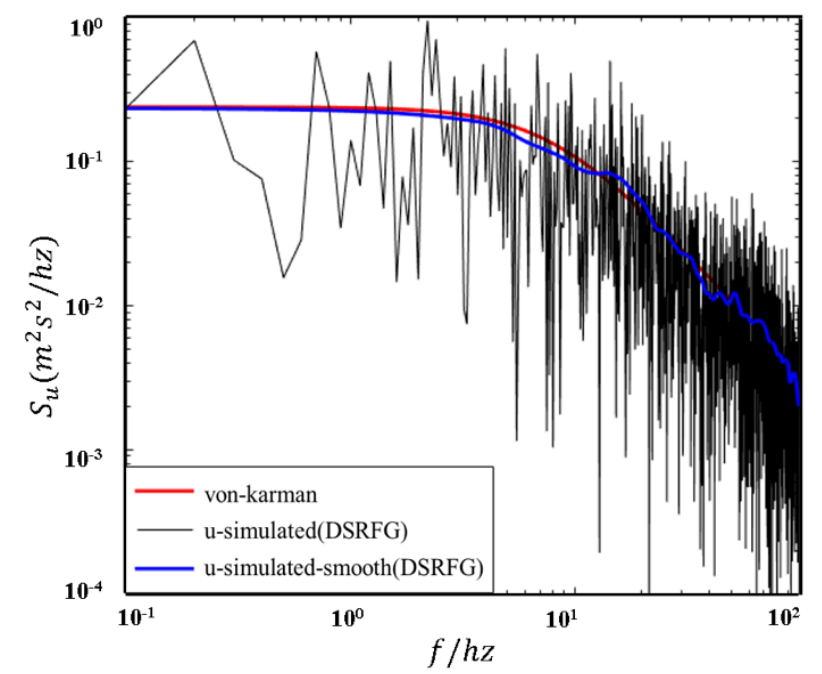

Fig. 1. Comparison of the spectrum by the DSRFG method and the target spectrum

\subsection{CFD calculation model}

A three-carriage (two head carriages and one middle carriage) high-speed train model was used. The model dimensions were 7.8 (length)*0.338 (width)*0.37 m (height), and the simplified train model is shown in Figure 3. The hexahedral computational domains under different wind fields were established, where $\mathrm{H}$ is the reference train height (4 m), as shown in Figures 4 and 5. The train model was placed in the computational domains. In this study, the hexahedral meshes were generated using STAR-CCM+, and three zones were set for mesh refinement, with the mesh quantity reaching 24 million. The cross-sectional meshes around the train model are shown in Figure 6. The velocities of different yaw angles were given at the velocity inlets. Under the condition of random wind, the lateral wind velocity inlet and pressure outlet were transformed into the periodic boundary conditions to solve the problem that the calculation of random wind model does not converge due to periodic pressure oscillation. A time-varying function was introduced into the boundary conditions to realize the ydirectional velocity of random wind, and it was transmitted into the computational domain of inlet boundary conditions at a constant velocity in the $\mathrm{x}$-direction.

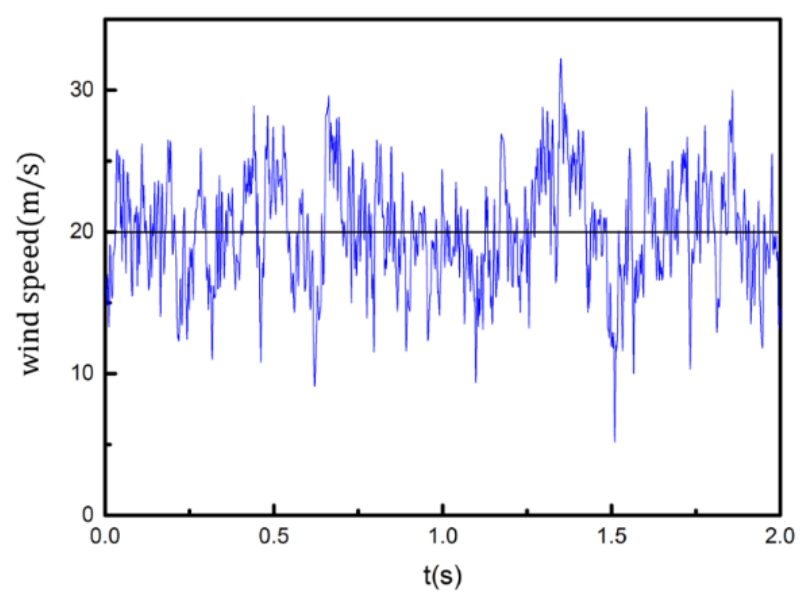

Fig. 2. Wind velocity simulated by the DSRFG method

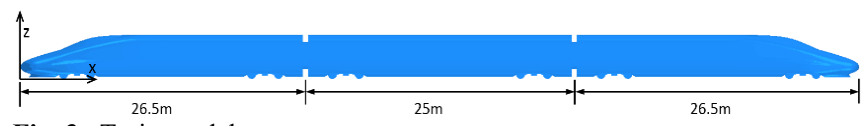

Fig. 3. Train model

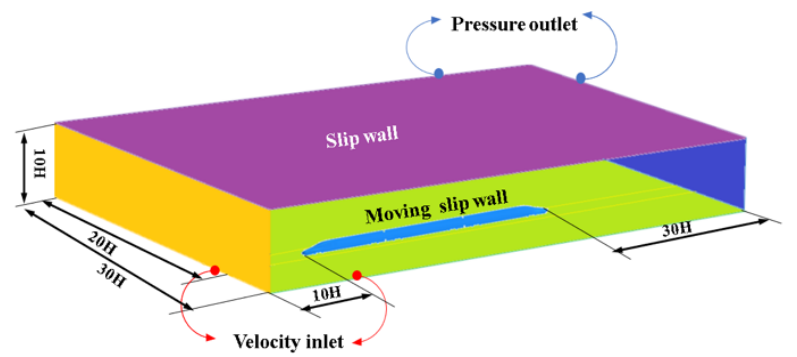

Fig. 4. Computational domain under steady wind field

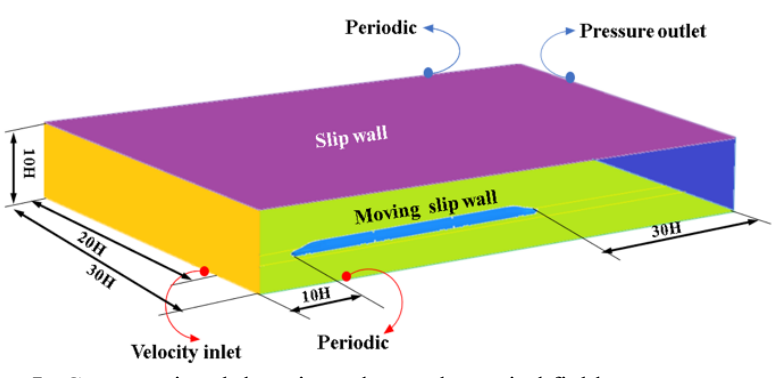

Fig. 5. Computational domain under random wind field

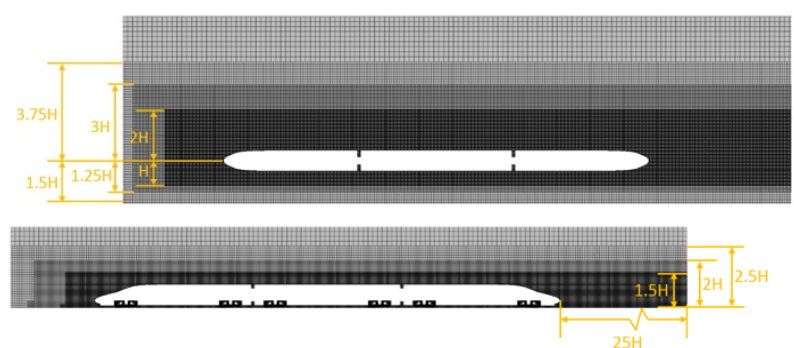

Fig. 6. Cross-sectional meshes 
The improved delayed detached eddy simulation (IDDES) method was selected as the calculation model. The detached eddy simulation (DES) model integrates the merits of large eddy simulation (LES) and Reynolds-averaged Navier-Strokes (RANS) equations. The near-wall smallscale pulsating movement was simulated via the RANS method, while the detached eddy away from the surface was simulated through the LES method. The traditional DES model is considerably sensitive to meshes, and the IDDES method based on DES can overcome the shortcoming of the DES model and improve the RANS ability to simulate the turbulent boundary layer. The specific equations of the IDDES method were defined, as seen in the literature [20]. The hybrid numerical method was used to transform the finite central difference method in the LES region and the second-order difference method in the URANS region to discretize the convective term. The turbulent flow was in the second-order difference format, while the time integral was in the second-order implicit format. In this study, the crosswind aerodynamic characteristics were simulated and calculated under the constant resultant velocity of $60 \mathrm{~m} / \mathrm{s}$ and yaw angles of $5^{\circ}, 10^{\circ}, 15^{\circ}$, and $20^{\circ}$.

\subsection{Train multibody dynamics model}

The aerodynamic performance of the head carriage of highspeed train is most greatly affected under crosswind conditions. Given that the coupling between vehicles is not considered, a vehicle system dynamic model for the head carriage of the train was established in this study. According to the main characteristics and components considered in the dynamic calculation, the vehicle was decomposed into one carriage body, two bogies, four wheelsets, and eight axle boxes. The vehicle body ran on the track at the degrees of freedom in six directions, namely, vertical, longitudinal, transverse, nod, shake, and side roll. The vehicle model is built from the bottom to the top. The degrees of freedom for each rigid body set through hinges. The suspension system could be divided into primary and secondary systems. The primary system mainly included primary springs and primary vibration dampers. The secondary system mainly contained air springs, anti-roll bars, secondary vibration dampers, and anti-yaw dampers, and the acting force of bump stops was considered. The structural diagram of the train model is shown in Figure 7. The vehicle shape does not affect the dynamic simulation calculation of the train system, and the structural and suspension parameters were selected according to the actual train parameters. The train dynamic model established via SIMPACK is shown in Figure 8.

The aerodynamic forces and moments must be loaded on the vehicle body to simulate the dynamic performance of the train under crosswind. The wind in the actual situation or flow field calculation can be uniformly applied to all positions on the vehicle body surface; however, the wind force can only be given to specific points in the dynamic calculation. In the SIMPACK simulation, the aerodynamic load was applied by adding the time incentive. Specifically, a coordinate point that moved with the vehicle was established at the center of its mass, and the time history function of the wind load was given into the time incentive through the input function, allowing the time-varying aerodynamic load to be applied to the vehicle body and the dynamic performance of vehicle multibody system under crosswind effect to be calculated.

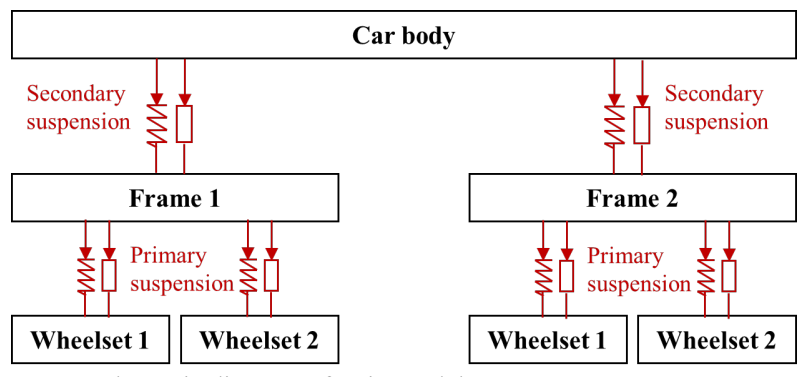

Fig. 7. Schematic diagram of train model structure

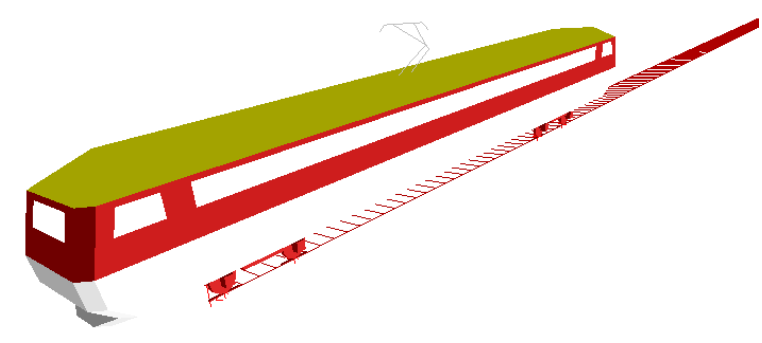

Fig. 8. SIMPACK model

\section{Result Analysis and Discussion}

\subsection{Aerodynamic load characteristics}

The change laws of the aerodynamic load coefficients under different types of wind fields and yaw angles were analyzed. The head carriage is most prone to overturning; thus, it was chosen for modeling in the subsequent dynamic analysis, and the resistance was not considered. The lateral force, lift force, overturning moment, pitching moment, and yawing moment of the head carriage were mainly analyzed in this study. The mean value, maximum value, and standard deviation of five aerodynamic load coefficients were considered. The change laws of the aerodynamic coefficients with yaw angle $\left(5^{\circ}-20^{\circ}\right)$ were acquired, as shown in Figure 9.

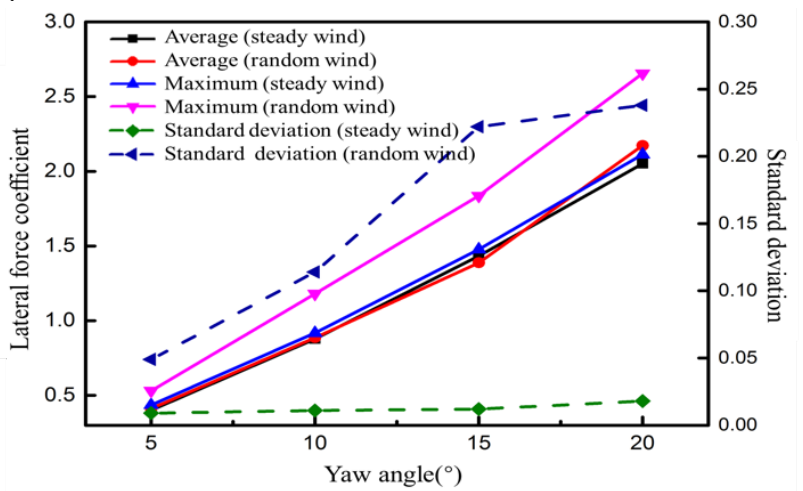

(a)

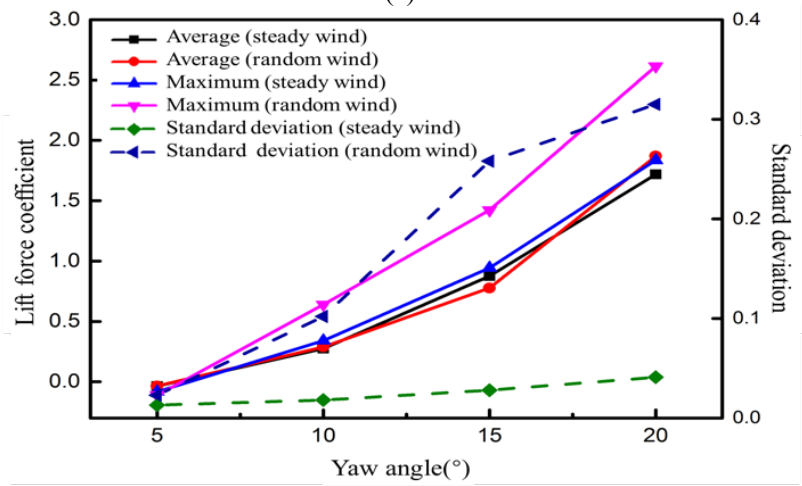

(b) 


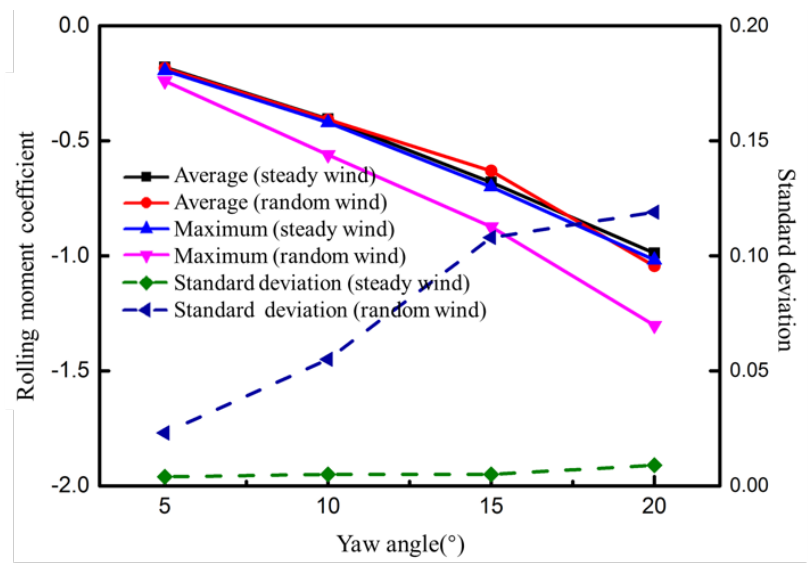

(c)

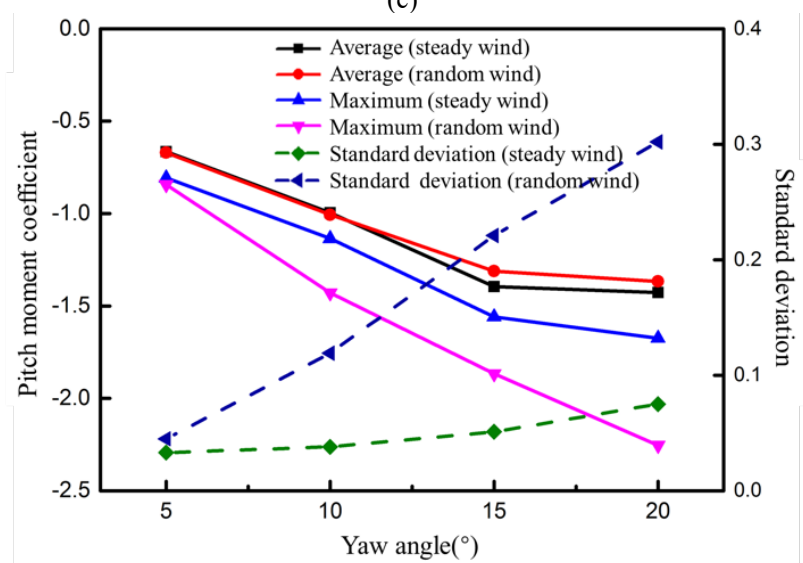

(d)

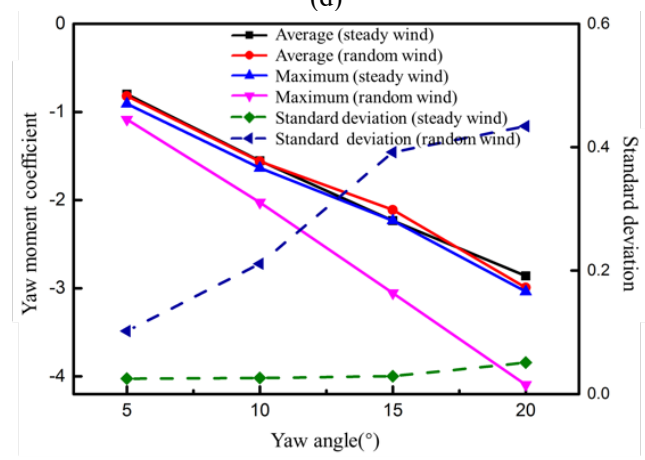

(e)

Fig. 9. Variation laws of aerodynamic coefficients with the yaw angle. (a) Latera force. (b) Lift force. (c) Rolling moment. (d) Pitch moment. (e) Yaw moment

The plus and minus signs of the aerodynamic load coefficients only represented the direction. The aerodynamic load coefficients showed similar change laws, and the lateral force coefficient was analyzed as an example. The mean value, maximum value, and standard deviation of each aerodynamic load coefficient increased along with the yaw angle under steady and random wind fields, and the greater the standard deviation, the more intense the pulsation of aerodynamic load coefficient with the increase in the yaw angle. The difference between the mean value of lateral force coefficient under steady wind and that under random wind did not exceed 3\%. The maximum value of the lateral force coefficient under random wind was much greater than that under steady wind, and their difference value in the maximum value increased with the enlargement of the yaw angle and even reached $26 \%$ at the yaw angle of $20^{\circ}$. The standard deviation of the lateral force coefficient under random wind was much greater than that under steady wind.
The standard deviation of the lateral force coefficient under steady wind was 0.018 at the yaw angle of $20^{\circ}$, and that under random wind was 0.238 , indicating that the change amplitude of lateral force was larger under the influence of pulsation characteristic of random wind.

\subsection{Train running safety indexes}

The fundamental requirement for railway transportation is running safety. To evaluate the train running safety, the main safety indexes referred to in this study included: overturning coefficient, wheel unloading rate, derailment coefficient, and wheelset lateral force. As the train running safety indexes intensely varied under a random wind effect, the mean and maximum values of the four safety indexes under a random wind effect were analyzed and comparatively analyzed with those under steady wind effect, as shown in Figure 10.

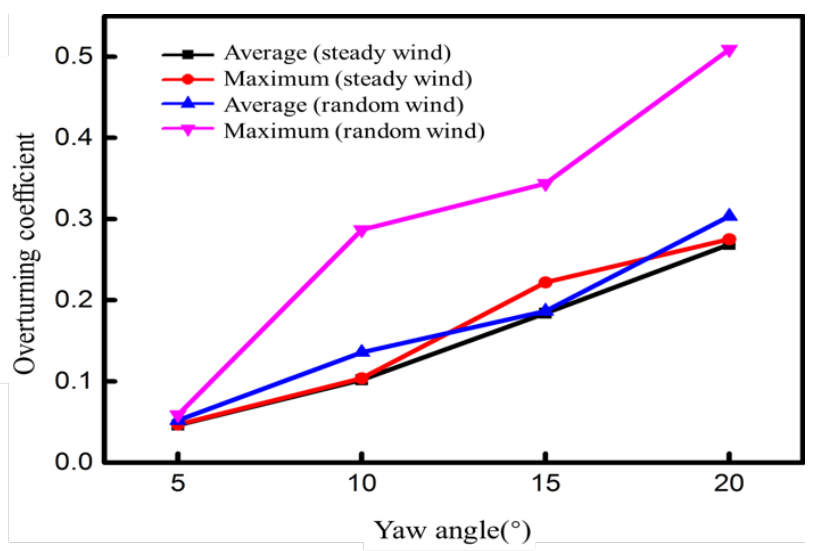

(a)

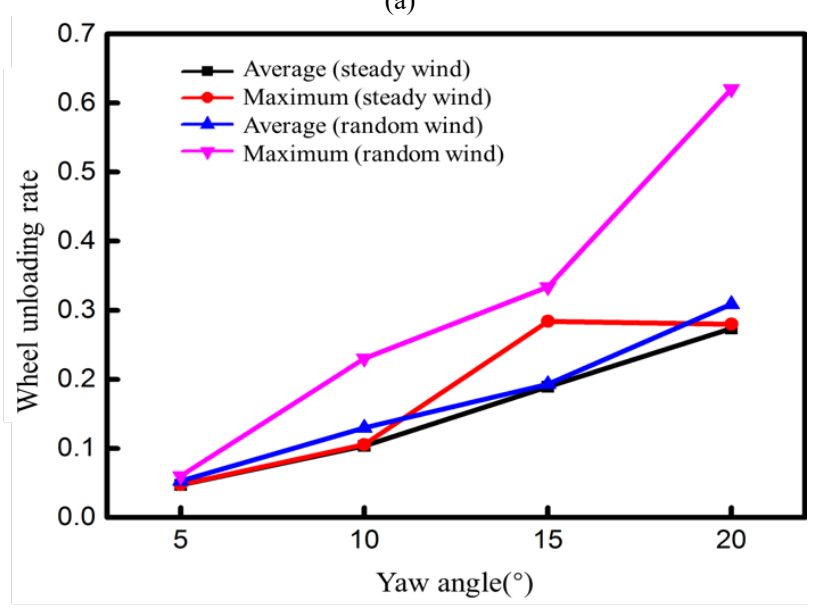

(b)

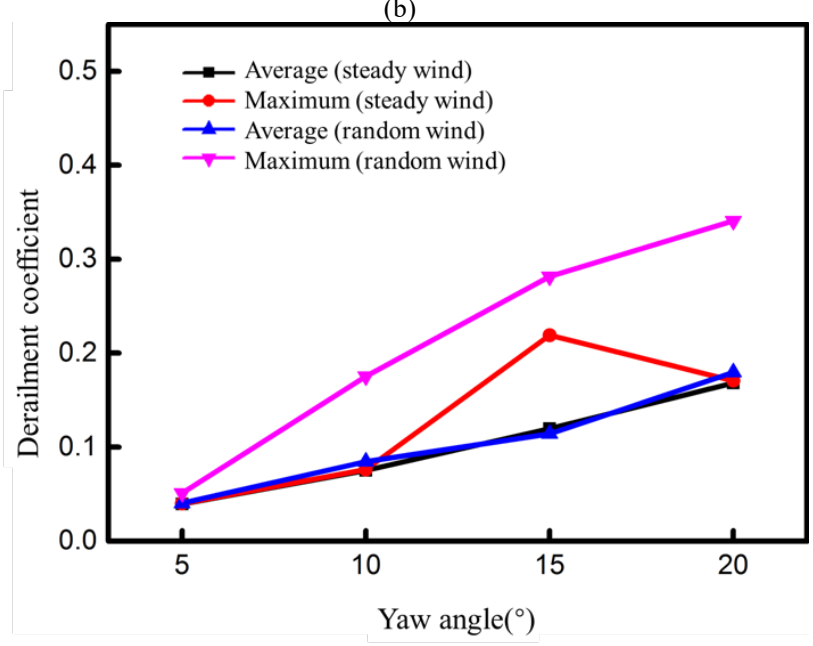

(c) 


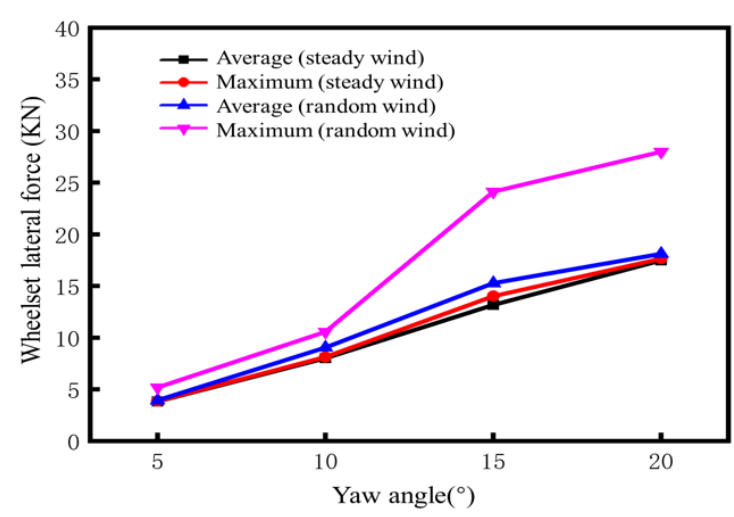

(d)

Fig. 10. Variation laws of safety indexes with the yaw angle. (a) Overturing coefficient. (b)Wheel unloading rate. (c) Derailment coefficient. (d)Wheelset lateral force

The change laws of each running safety index were similar under different wind load effects. The difference between the mean and the maximum values of each safety index was minor under the steady wind load effect, indicating that the aerodynamic loads slightly pulsated under steady wind; hence, the train safety indexes also slightly pulsated under a steady wind load. The mean value of each train running safety index was always higher than that under steady wind load under a random wind load effect; nonetheless, the difference was not large. The maximum value of the train running safety indexes far exceeded the mean value under a random wind load effect. The maximum value of the overturning coefficient under random wind at a yaw angle of $20^{\circ}$ exceeded the mean value by $68 \%$, the wheel unloading rate by $\sim 100 \%$, the derailment coefficient by $\sim 89 \%$, and the wheelset lateral force by $\sim 101 \%$. This finding revealed that the corresponding aerodynamic loads under the two wind fields were similar when the average wind speed of steady wind and random wind was the same. However, the pulsation of random wind affected the change amplitude of the train aerodynamic load and its peak value, thus influencing the train running safety indexes. The mean and maximum values of each train running safety index under different wind load effects increased with the increase in the yaw angle. The larger the yaw angle, the greater the difference between the maximum and the mean values of the safety index under random wind, manifesting that the pulsation of train running safety index under random wind load effect was strengthened with the increase in the yaw angle.

The wheel unloading rate and overturning coefficient are taken as the main evaluation indexes of vehicle safety. With regard to the vehicle dynamic response under steady and random wind fields, the change amplitude of the dynamic safety indexes of trains under random wind field is larger. Therefore, enough safety margin should be reserved for train running safety, and it is more reasonable to adopt the unsteady aerodynamic and dynamic calculations under random wind field.

\subsection{Evaluation of train safety indexes under random wind effect}

The train running safety index under steady wind load will approach a stable value, but it is a continuously fluctuating change curve under a random wind load. The transient fluctuation of the train running safety index is drastic, and the index changes within a short time; thus, it is not reasonable enough to purely take its maximum value as the judgment value. Accordingly, filtering processing was considered in this study. The change curves were filtered under different frequencies $(10,20,30$, and $40 \mathrm{~Hz})$. The mean value of index curve under different filtering frequencies was compared with the value under steady wind, as shown in Figure 11. A large difference was observed between the mean values of the index under 30 and $40 \mathrm{~Hz}$ filtering and those under steady wind, and the mean values of the index under 10 and $20 \mathrm{~Hz}$ filtering were approximate to those under steady wind. A few points of the curves after filtering under $10 \mathrm{~Hz}$ were quite different from the target, and the mean values after filtering under $20 \mathrm{~Hz}$ were in good agreement with those under steady wind. Therefore, the frequency of $20 \mathrm{~Hz}$ was more appropriate for filtering the variation curve of the train running safety indexes under random wind. With the overturning coefficient taken for example, the changes in its maximum value under random wind relative to that under steady wind at the filtering frequency of $20 \mathrm{~Hz}$ were analyzed, as illustrated in Table 1. After filtering under $20 \mathrm{~Hz}$, the maximum value of overturning coefficient slightly changed at a small yaw angle, such as $5^{\circ}$. At larger yaw angles, the maximum values of overturning coefficient under random wind were approximately $20 \%-30 \%$ higher than that under steady wind. Hence, the influence of random wind on the train running safety should be investigated at different yaw angles.

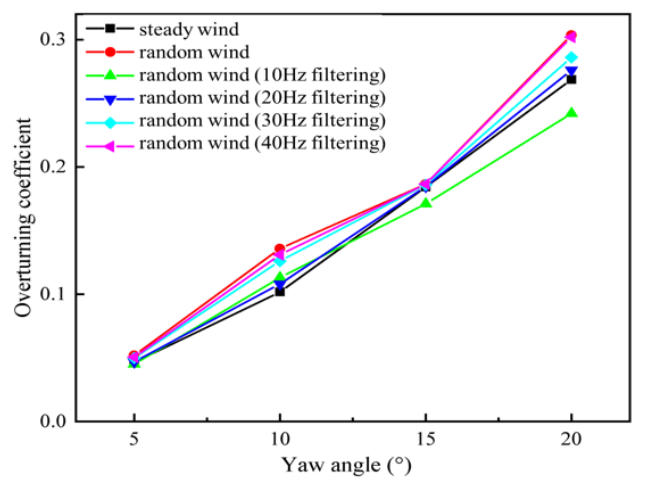

(a)

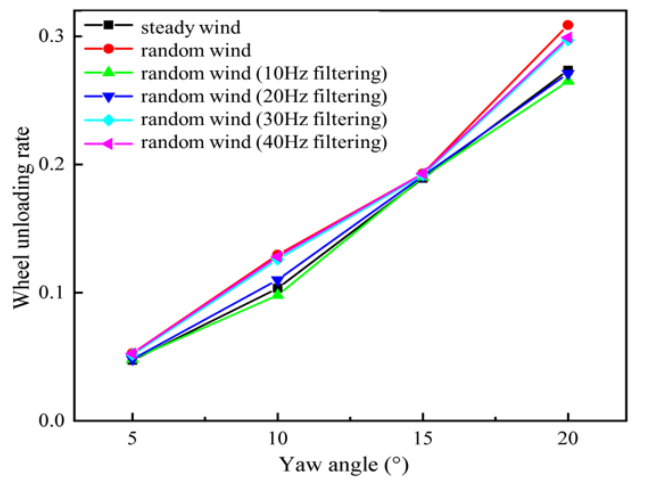

(b)

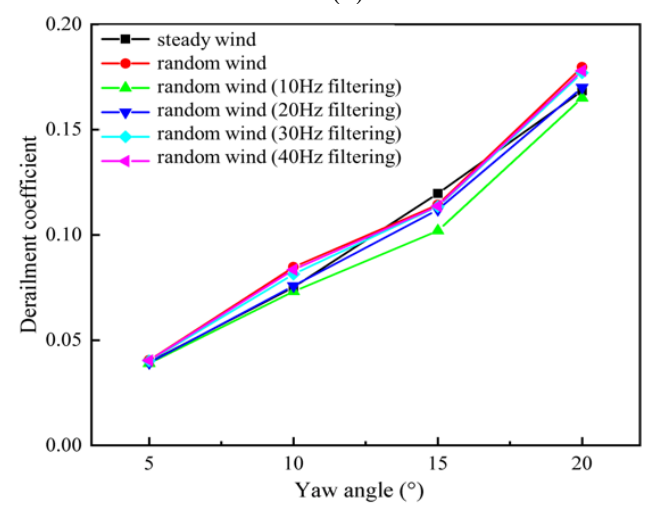

(c) 


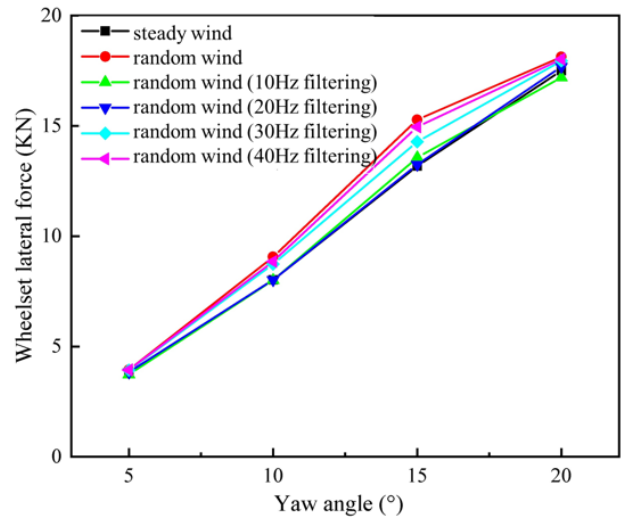

(d)

Fig. 11. Comparison of safety indexes under random and steady wind after filtering. (a) Overturing coefficient. (b)Wheel unloading rate. (c) Derailment coefficient. (d)Wheelset lateral force

Table 1. Maximum overturning coefficient under $20 \mathrm{~Hz}$ filtering

\begin{tabular}{c|c|c|c}
\hline $\begin{array}{c}\text { Yaw } \\
\text { angle } \\
\left({ }^{\circ}\right)\end{array}$ & $\begin{array}{c}\text { Random wind } \\
(\mathbf{2 0 H z} \text { fitering) }\end{array}$ & Steady wind & $\begin{array}{c}\text { Percentage } \\
\text { difference } \\
\mathbf{( \% )}\end{array}$ \\
\hline 5 & 0.051 & 0.047 & 8.5 \\
10 & 0.137 & 0.104 & 31.6 \\
15 & 0.269 & 0.222 & 21.2 \\
20 & 0.345 & 0.275 & 25.5 \\
\hline
\end{tabular}

\section{Conclusions}

The pulsating crosswind was generated to study the influence of random wind on the high-speed train running safety, and the CFD calculation and multibody system dynamic simulation were combined to comparatively analyze the aerodynamic load characteristics and train running safety indexes under steady and random wind models. The following conclusions could be drawn:

(1) The aerodynamic load characteristics of train under different wind field effects were compared. The mean values of all aerodynamic load coefficients under different wind fields slightly varied. The maximum value and standard deviation under random wind are greater than those under steady wind. The maximum value, mean value, and standard deviation of each aerodynamic load coefficient increase with the enlargement of the yaw angle, and the pulsating effect of random wind is more obvious.

(2) The train running safety indexes under different wind fields were compared. The mean and maximum values of each index under steady wind load are not much different. The maximum value of each index under random wind far exceeds the mean value. The influence of pulsation of random wind load on the train running safety indexes intensified with the increase in the yaw angle. The mean value of the $t$ index under random wind is almost greater than that under steady wind. It is more conservative to use the random wind load to evaluate the train running safety indexes.

(3) The change curves of train running safety indexes were filtered under random wind and compared with the changes in the mean values under steady wind. The result indicated that the filtering under $20 \mathrm{~Hz}$ is relatively reasonable. The maximum value of overturning coefficient curves under random wind after the $20 \mathrm{~Hz}$ filtering is approximately $20 \%-30 \%$ higher than that under steady wind.

The pulsating wind was only loaded in the transverse direction in this study; however, the wind in nature is of pulsation in all three directions. The random wind should be simulated by fully considering the pulsation in two or three directions. This task is necessary to more accurately simulate and analyze the unsteady aerodynamic characteristics and running safety of trains under the random wind effect.

\section{Acknowledgements}

The authors are grateful for the support provided by Natural Science Foundation of Anhui University of Science and Technology (Grant No. QN2019122) and the National Natural Science Foundation of China (Grant No. 51874006).

This is an Open Access article distributed under the terms of the Creative Commons Attribution License.

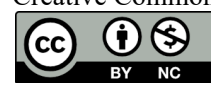

\section{References}

1. Noguchi, Y., Nakade, K., "Numerical simulations of the wind tunnel tests on the aerodynamic characteristics of trains in the crosswind". Quarterly Report of RTRI, 59(2), 2018, pp. 115-120.

2. Montenegro, P. A., Rui, C., Carvalho, H., Bolkovoy. A., Chebykin. I.., "Stability of a train running over the volga river high-speed railway bridge during crosswinds". Structure and Infrastructure Engineering, 16(8), 2020, pp. 1121-1137.

3. Liu, T. H., Chen, Z. W., Zhou, X. S., Zhang, J., “A CFD analysis of the aerodynamics of a high-speed train passing through a windbreak transition under crosswind". Engineering Applications of Computational Fluid Mechanics 12(1), 2018, pp. 137-151.

4. Miao, X., He, K., Minelli, G., Zhang, J., Krajnovic, S., "Aerodynamic performance of a high-speed train passing through three standard tunnel junctions under crosswinds". Applied Sciences, 10(11), 2020, pp. 3664.

5. Yang, L. F., Yang, X. X., "Study on aerodynamic characteristics of high-speed train running at part-cut and part-fill railway section under crosswind". Journal of East China Jiaotong University, 036(003), 2019, pp. 1-6.

6. Zhou, P., Chang, C., Li, T., Qin, D., "Effect of Suspension-system Parameters on Crosswind Stability of High-speed Trains". Journal of Transportation Engineering and Information, 18(04), 2020, pp. 83-92.
7. Liu, D. Y., Tomasin, G. M., Rocchi, D., Cheli, F., Zhong, M., "Correlation of car-body vibration and train overturning under strong wind conditions". Mechanical Systems and Signal Processing, 142, 2020, pp. 106743.

8. Deng, E., Yang, W. C., Lei, M. F., Zhu, Z. H., Zhang, P, P., "Aerodynamic loads and traffic safety of high-speed trains when passing through two windproof facilities under crosswind: A comparative study". Engineering Structures, 188, 2019, pp. 320339.

9. Baker, C. J., "Ground vehicles in high cross winds part II: Unsteady aerodynamic forces". Journal of Fluids and Structures, 5, 1991, pp. 91-111.

10. Zhang, T., Zhang, N., Wang, S. Q., Xia, H., "Crosswind safety analysis for train running on a bridge based on reliability theory". Journal of Vibration and Shock, 38(17), 2019, pp. 226-231.

11. Zhang, L., Zhang, J., Y., Li, T., "Unsteady aerodynamic characteristics and safety of high-speed trains under crosswinds". Journal of Mechanical Engineering, 52(6), 2016, pp. 124-135.

12. Cooper, R. K., "Atmospheric turbulence with respect to moving ground vehicles". Journal of Wind Engineering and Industrial Aerodynamics, 17(2), 1984, pp. 215-238. 
13. Ding, Y., Sterling, M., Baker, C. J., "An alternative approach to modeling train stability in high cross winds". Proceedings of the Institution of Mechanical Engineers Part F: Journal of Rail and Rapid Transit, 22(20), 2008, pp. 85-97.

14. Baker, C. J., Hemida, H., Iwnicki, S., G, Xie., Ongaro, D., "Integration of crosswind forces into train dynamic modelling". Proceedings of the Institution of Mechanical Engineers Part $F$ Journal of Rail \& Rapid Transit, 225(F2), 2011, pp. 154-164.

15. Xu, Y. L., Ding, Q. S., "Interaction of railway vehicles with track in cross-winds". Journal of Fluids and Structures, 22(3), 2006, pp. 295-314.

16. Tan, S. F., Miao, B. R., Yang, J. K., Wang, M. Y., “Calculation and simulation for unsteady aerodynamic loads of high-speed trains under crosswind". Chinese Hydraulics and Pneumatics, 000(002), 2016, pp. 30-35.
17. Yu, M. G., Jiang, R. C., Zhang, Q., Zhang, J. Y., "Crosswind stability evaluation of high-speed train using different wind models". Chinese Journal of Mechanical Engineering, 032(003), 2019, pp. 168-180.

18. Peng, Y. K., Luo, R., Hu, J, B., Li, R., "Research on safety of high speed trains under different crosswind Models." Rolling Stock. 53(09), 2015, pp.5-10.

19. Huang, S. H., Li, Q. S., Wu, J. R., “A general inflow turbulence generator for large eddy simulation". Journal of Wind Engineering and Industrial Aerodynamics, 98(10-11), 2010, pp. 600-617.

20. Shur, M. L., Spalart, P. R., Strelets, M. K., "A hybrid RANS-LES approach with delayed-DES and wall-modelled LES capabilities". International Journal of Heat and Fluid Flow, 29(6), 2008, pp. 1638-1649. 